\title{
1 Cropland yield divergence over Africa and its 2 implication for mitigating food insecurity
}

3 Authors: Yibo Luan, Wenquan Zhu, Xuefeng Cui, Günther Fischer, Terence P. Dawson,

4 Peijun Shi, Zhenke Zhang

5 The corresponding author is:

6 Dr. Prof. Peijun Shi

7 Affiliation: State Key Laboratory of Earth Surface Processes and Resource Ecology;

8 Academy of Disaster Reduction and Emergency Management, Ministry of Civil Affairs \&

9 Ministry of Education; Faculty of Geographical Science, Beijing Normal University,

10 Beijing 100875, China

11 E-mail: spj@bnu.edu.cn

Mail and email addresses, Affiliations of all contributors: Yibo Luan, PhD

Affiliation: School of Geography and Ocean Science, Nanjing University, Nanjing, Jiangsu Province, 210023, China

E-mail:whuyimu@hotmail.com

\section{Dr. Prof. Wenquan Zhu}

Affiliation: State Key Laboratory of Earth Surface Processes and Resource Ecology, Beijing Engineering Research Center for Global Land Remote Sensing Products, Institute of Remote Sensing Science and Engineering, Faculty of Geographical Science, Beijing Normal University, Beijing 100875, China

E-mail: zhuwq75@bnu.edu.cn

\section{Dr. Xuefeng Cui}

Affiliation: School of Systems Science, Beijing Normal University, Beijing 100875, China

E-mail: xuefeng.cui@bnu.edu.cn

\section{Günther Fischer}

\section{Affiliation: WAT, International Institute for Applied Systems Analysis, International} Institute for Applied Systems Analysis (IIASA) - Schlossplatz 1 A, 2361 Laxenburg, Austria

\section{E-mail: fisher@iiasa.ac.at}

\section{Dr. Prof. Terry P. Dawson}

Affiliation: Department of Geography, King's College London, King's College London,

Strand, London, United Kingdom

E-mail: terry.dawson@kcl.ac.uk

Dr. Prof. Zhenke Zhang 
Affiliation: School of Geography and Ocean Science, Nanjing University, Nanjing, Jiangsu

Acknowledgments: This work was supported by the National Science Foundation of China (NSFC; Grant no. 41271542) and by the National Key Research and Development Plan under Grant no. 2016YFA0602404, Ministry of Science and Technology of China (MSTC), People's Republic of China. Edinburgh Research and Innovation of the University of Edinburgh kindly provided the GEnS data. The first author gratefully acknowledges the Chinese Scholarship Council (CSC) for funding the research conducted at the International Institute for Applied Systems Analysis (IIASA), and Luzma Fabiola Nava (affiliated research scholar at IIASA) for providing English language support. Comments and suggestions from Dr. Laixiang Sun and the anonymous reviewers are also gratefully

54 appreciated.

55 Author Contributions: Xuefeng Cui, Yibo Luan and Wenquan Zhu conceived and designed the research study; Peijun Shi, Xuefeng Cui supervised the research; meanwhile Günther Fischer contributed datasets. Yibo Luan processed the data and wrote the paper. Yibo Luan, Wenquan Zhu, Günther Fischer, and Terry P. Dawson contributed to analysis and discussion of this research. All co-authors contributed to manuscript revise.

60

Conflicts of Interest: The authors declare no conflict of interest.

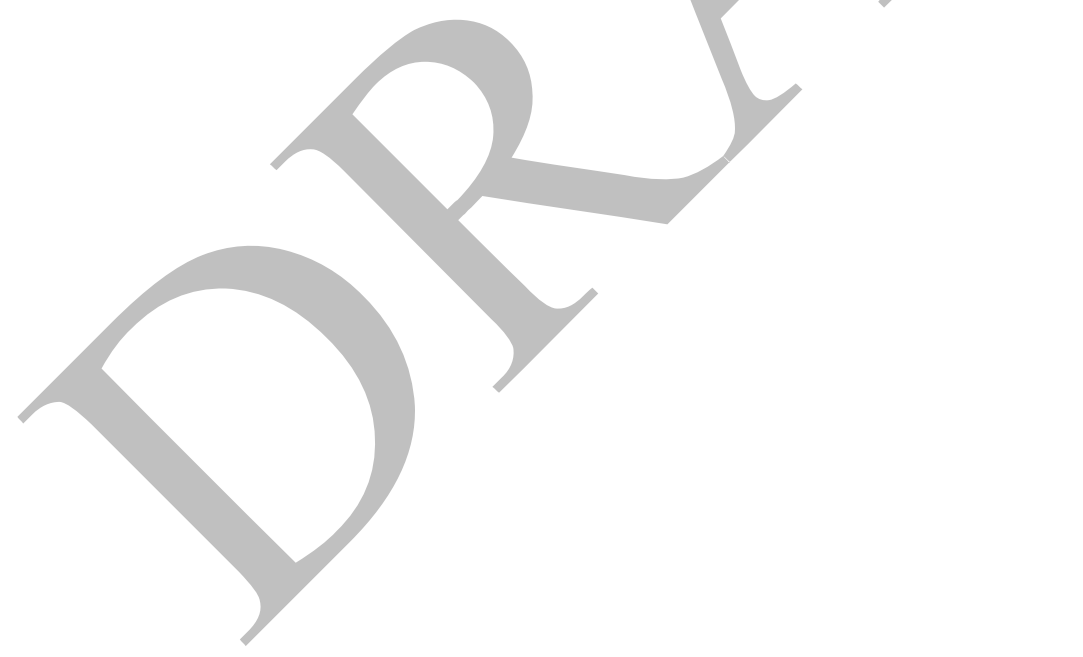




\section{Introduction}

Despite globalization and the scale of international food trade, access to sufficient food remains a major challenge in Africa, particularly in Sub-Saharan Africa, which accounts for $\sim 19 \%$ of the world's undernourishment in 2015-2017 (FAO et al. 2017) and even higher than 2014-2016. Food security and nutrition in Africa is still at the heart of Africa's development agenda. Currently, many countries and subregions in Sub-Saharan Africa depend on imports to fill up to a third of their cereal needs, suggesting that substantial demand for food exists for these countries, and calling a need to increase agricultural productivity and food production (FAO 2017; van Ittersum et al. 2016). Meanwhile, population growth, dietary preference towards resource-intensive foods, and achieving a world without hunger and malnutrition - an aim set by the second Sustainable Development Goal (SDG2) (FAO 2017), companioning with challenges from climate change on land resources and crop yield (Dawson et al. 2016), put significant pressure on Africa's food security situation (Godfray et al. 2010).

Stagnant crop production is one of major contributors to food insecurity in Africa, but it is not because of lacking cropland. Africa land availability per capita $(0.25 \mathrm{ha})$ is higher than the world average (0.22ha) (FAOSTAT 2017). Additionally, the fraction of fallow cropland to total cropland is very high (Monfreda et al. 2008; Lobell 2013). Cropland systems in Africa are characterized as lowexternal-input, rain-fed and low-yield (Luan et al. 2013). Though growth in total factor productivity is the most important source of growth in global agricultural production in the past two decades, in Sub-Saharan Africa the productivity grew by less than $1 \%$ per year over that period, and far lower than world average level (FAOSTAT 2017).

Narrowing gaps between actual farm yields and yield potential is widely regarded as an important strategy to meet current and future food demand (Foley et al., 2011). Theoretically, the yield-gap is the difference between yield potential that could be achieved in situations with no water and fertilizer restrictions and the average farmer's actual yield over a specified spatial and temporal scale of interest (Lobell et al. 2009). According to this definition, broadly there are three methods of assessing yield-gaps: (i) field-scale studies including field experiments and yield contests, (ii) crop 
model simulations, and (iii) studies using maximum yield achieve, providing three kinds of yieldgaps applicable at different scales (van Ittersum et al. 2013). Many studies have done works on assessing regional or global crop yield potential and related yield-gaps, and some studies argues that it is possible to meet projected future regional or global food demand on existing agricultural land by filling up the yield-gaps (Duku et al. 2018; Erb et al. 2016; Mauser et al. 2015; Mueller et al. 2012; Pradhan et al. 2015; Tilman et al. 2011). Most of these studies focuses on meeting projected scenarios, and using calculated yield-gaps mainly by crop model simulations or yield experiments which could provide agronomic potential yield and water-limited potential yield (van Ittersum et al., 2013). Although meeting the future demand may be possible, and indeed it is important to answer questions about whether and how to guarantee our future, whether different African countries would meet their basic food demands by adoptable best cultivating practices observed on current cropland is also need to be concerned.

In reality, reaching a potential level of yield is prevented by a number of biotic and abiotic stresses, including: soil fertility or lack of fertilization, water availability, cultivar features (van Ittersum et al. 2013), and market access, etc. Given a specific biophysical and socio-economic environment, farmers try to maximize production or income after a consideration of all farming constraints. In any case, their efforts produce widely different results representing as yield divergence. Therefore, identifying and quantifying hotspot of yield divergence is an initial but essential step towards mitigating food insecurity by observing and adopting best regional agricultural practices.

Spatial cropland yield divergences in agro-climatic homogeneous zones usually imply gaps which have potential to be closed up and then improve the local productivity by adopting currently observed best cultivating practices in the same zone. Such gaps could be observed and measured by maximum yield achieved method (van Ittersum et al. 2013; van Wart et al. 2013). Different from fieldscale studies and model simulations, the maximum yield achieved method compares yield to the observed maximum value achieved inside a region varying in size from landscape to agroecosystems. Currently, spatial yield data used to derive yield-gaps are often based on country-level data (e.g. Licker et al. 2010; Johnston et al. 2011; or FAOSTAT 2017), or data from a particular year (e.g. SAGE datasets) of spatial yield values in coarse resolution. Such cases largely depend on external sources (e.g. Monfreda et al. 2008) and are characterized by absence of real-time monitoring, and multi-year values.

Satellite data provide a unique opportunity to overcome both spatial and temporal scaling challenges (Atzberger 2013; Lobell 2013). Multiple sensors, especially the Moderate Resolution Imaging Spectroradiometer (MODIS) have generated time-series of remote sensing imagery that enable monitoring of the intra-annual, and inter-annual, dynamics of vegetation growth. The repeat coverage of remote sensing enables extracting the key points of crop growth period at pixel level to increase the accuracy of simulating crop yields (Duncan et al. 2015b). Satellite data also enable appropriate representation of spatially heterogeneous agricultural systems. Because of these characteristics, in the past decades, many studies have used established relationships between vegetation indices and crop yields to map and monitor crop yield distribution (Bolton and Friedl 2013; Huang et al. 2013; Duncan et al. 2015a; Burke and Lobell, 2017).

This study aims to assess currently whether African countries have capacity to mitigate their food shortages (on energy unit) by yield gaps between preferable attainable yield from currently observed best cultivating practices and actual yield. This is achieved by using the modified Local NPP Scaling (LNS) method proposed by Prince (Prince et al. 2009) on the growing season NDVI integral (GSI) (Funk and Budde 2009; Mkhabela et al. 2011). The LNS method is applied on cropland of African continent, and the GSI is chosen to represent cropland productivity derived from the MODIS datasets. Firstly, the difference between the observed preferable attainable yield and the actual yield in one same homogeneous agro-climatic zone is calculated and termed as currently attainable potential yield gap (CAYgap) of this zone. The CAYgap could be denoted as yield-gaps measured by maximum yield achieved method. Then, the CAYgap is converted to cereal equivalent (CE) measured unit, and furthermore, is used to estimate the relevant potential production gap of 
each country. Finally, we use these production gaps to assess the capacity of each country to mitigate

\section{Materials and Methods}

In this study, all herbaceous crops were aggregated and converted into cereal equivalent (CE). Here, the maximum yield in a target region was denoted as the currently attainable potential yield (CAYpotential) for the rest of the region; this was different from the agronomical potential yield. The gap between actual achieved yields and CAYpotential (denoted as CAYgap) was used to map the extent of regional yield divergence in respective agro-climatic zones and estimate the regional currently attainable potential production (CAPpotential). Materials used in this study and calculating flows is presented as Fig. 1, detailed descriptions of each step is described in following sections.

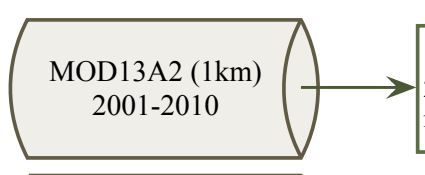

1. Savitzky-Golay filter method 2. White phenological extraction method

GlobCover2009 dataset $(300 \mathrm{~m})$

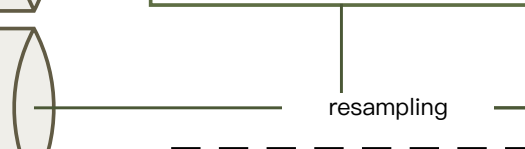

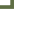

\section{,}

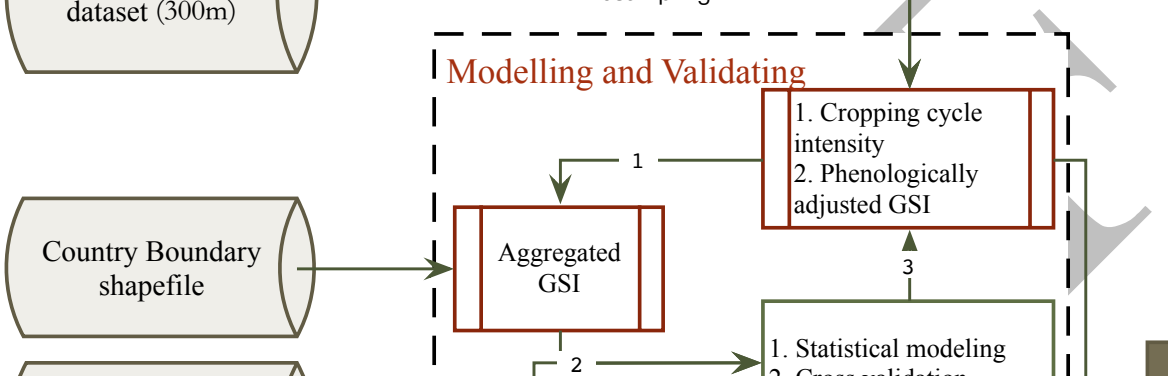

Additional population fed by currently attainable potential production gap
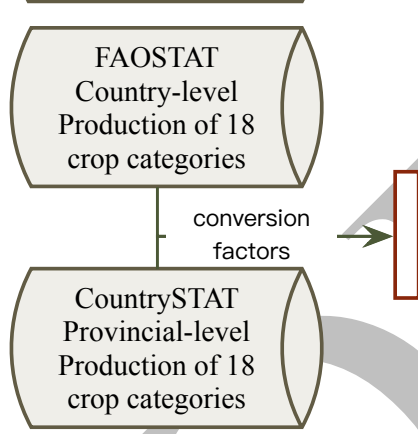
2. Cross validation

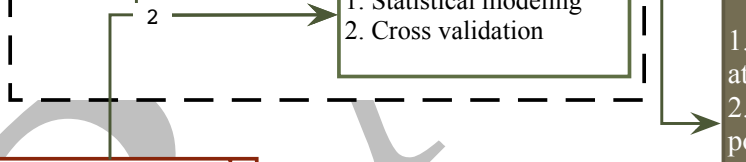

Distribution of currently attainable potential yield gap 2. Currently attainable

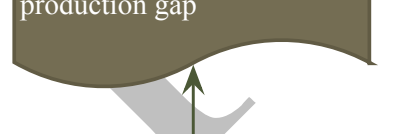

Fig.1 Calculating flowchart

\subsection{Data sources and data pre-processing}

\subsubsection{Datasets of cropland and agro-climatic zones}

To constrain the homogenous zones for upscaling potential yields, Global Environmental Stratification (GEnS) was used to characterize agro-climatic zones (Metzger et al. 2013). GEnS achieves a suitable balance between the number of zones needed for coverage of harvested areas and the homogeneity of agro-climatic variables within zones (van Wart et al. 2013). The cropland distribution layer, at a resolution of $1 \mathrm{~km}$, was obtained and upscaled from the GlobCover 2009 database (Global Land Cover Map) with resolution of 300m (Bontemps et al. 2011). Four classes were considered: (1) post-flooding or irrigated croplands, (2) rain-fed croplands, (3) mosaic cropland (50$70 \%$ )/vegetation $(20-50 \%$ ) and, (4) mosaic vegetation (50-70\%)/cropland (20-50\%). The weighting of the cropland ratio of each pixel was set as 1.0 for classes (1) and (2), and a mean weight of 0.65 and 0.35 was assumed for classes (3) and (4), respectively. Irrigated cropland was included because its proportion of the complete study region was small ( $\sim 5 \%$ from GlobCover 2009$)$. 
Satellite data used in this study came from the Terra MODIS Normalized Difference Vegetation Index (NDVI) 1-km product (MOD13A2, collection 5). The studying period was 2001-2010 in order to preferably match the time of other data. The iterative Savitzky-Golay filtered algorithm (Chen et al. 2004) was then applied to eliminate the noise caused by persistent cloud contamination, atmospheric variability, and bi-directional effects before extracting the phenological metrics. To eliminate the interference of soil background and cloud effects, and to exclude contaminated pixels, masking was performed on those pixels that had a 10-year average NDVI outside of the 0.1-0.8 range or those with a coefficient of variation of less than 0.1 (Vrieling et al. 2011).

\subsubsection{Agricultural statistics}

Three sources of agricultural statistics were used to train the relationship of cereal equivalent and growing season NDVI integral (GSI): the country-level data from FAOSTAT (2017), the provincial-level data from CountrySTAT (Kasnakoglu), and Agro-Maps (FAO et al. 2006). Statistics at the second administrative level were not included.

Seven crop categories were grouped into one index, the cereal equivalent (CE), using cereal equivalent conversion coefficients (Rask and Rask 2014) as: cereals (1.0); starchy roots (0.25); sugar, sweeteners (1.08); pulses (1.06); vegetable oils primary (2.72); vegetables primary (0.08); and fruit (0.14). All crops in each category were on a primary level. Sugarcane and sugar beet were converted into sugar primary by using a unified extraction ratio of $12 \%$ (crop production weighted world average). Cottonseed was allocated into the vegetable oil category by using a world average extraction ratio of 0.63 (FAO 2000). Tree nuts and vegetable oil were excluded because they were sourced primarily from evergreen trees.

FAOSTAT was set as the priority data due to its spatial and temporal availability. The principle of selecting provincial-level data from CountrySTAT was based upon the following assumption: (i) aggregated CE production of cereals and starchy roots and (ii) aggregated CE production of all crops from provincial-level data should be similar to the amount calculated from FAOSTAT (ratio of CountrySTAT's CE to FAOSTAT's CE ranged from 0.8 to 1.2). On this basis, a total of 10 countries were selected (accumulated 70 years' data).

Several countries were excluded from this study due to insufficient data: Comoros, Sao Tome and Principe, Cape Verde, and Western Sahara were missing GSI or statistical data. Four countries were also excluded during training the CE models of GSI: (i) DR Congo, Congo-Brazzaville, and Madagascar were missing most cropland GSI data due to adjacency contamination from forests and woods on NDVI profiles of cropland; (ii) Egypt, where almost all cropland was irrigated. Sudan and South Sudan were combined as Sudan (former) because they were politically delineated in 2011, after the study period took place.

\subsection{Methodology}

\subsubsection{Extraction of vegetation phenological metrics}

In the current study, the threshold method proposed by White (White et al. 1997) was used to extract the phenological metrics from NDVI profiles: start of season data (SOS), end of season (EOS), and length of season between SOS and EOS (LOS; Fig. 2). This method was considered to be the simplest and moderately effective for phenological study (White et al. 2009; de Beurs and Henebry 2010). 


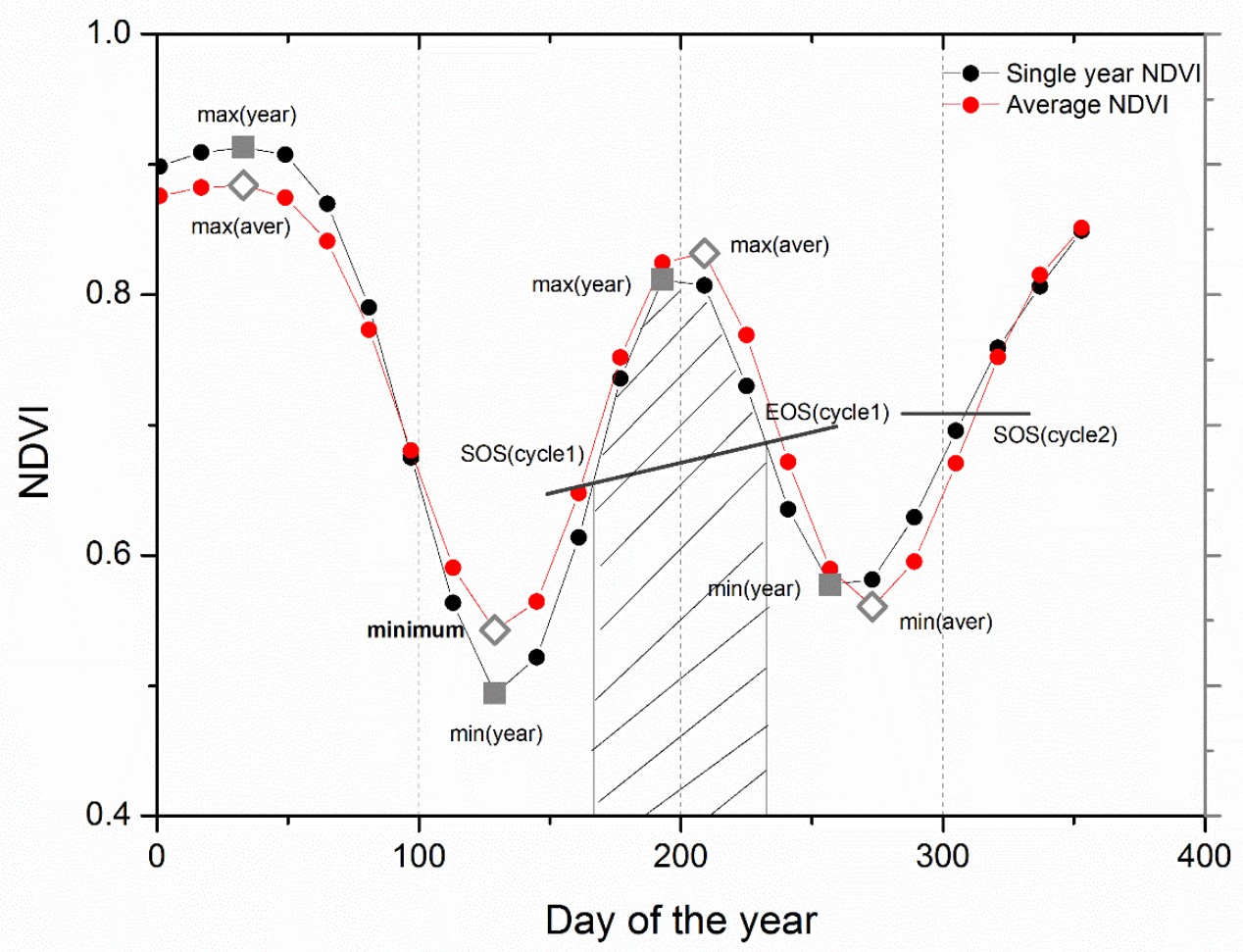

Fig. 2 Illustration of the method used to extract phenological metrics. The presented two time-series NDVI profile a two-growth cycle pixel for one year and its 10-year average respectively. There are two minima in the one-year profile. Two SOS values in this year are counted, and the one nearer to the advent of the minimum of 10 -year average profile is the SOS for growth cycle 1 , the other is for cycle 2. The dashed area is the GSI for each pair of SOS and EOS.

Phenological extraction for continental Africa is complex because growing seasons span different calendar years and double growing seasons over one calendar year occur only in some regions. A method that was developed by Anton Vrieling (2011) was adopted with several refinements. First, the growth cycle intensity was calculated and each growth cycle was identified based on Biradar and Xiao's (2011), and Liu's studies (2012). Each growth cycle was determined as the period between two minima NDVI, which were the lowest values in a window of 112 days (7 images of 16-day resolution). Because the study targeted herbaceous crop, growth cycle would be excluded if it had a growth amplitude (the gap between the maximum and minimum values in one growth cycle) less than 0.1 (Heumann et al. 2007) and/or with a time span shorter than 2 months (Liu et al. 2012), in order to weaken the impact of natural vegetation growth on crop growth. The maximum and minimum growth amplitudes of each pixel's NDVI time-series profile were also excluded to remove outliers in the calculation of 10-year average intensity.

Second, phenological metrics of each growth cycle were extracted and recorded. A yearly average NDVI profile for 2001-2010 was constructed and the minimum NDVI value of this profile was determined for each pixel. Then, for each pixel and for each year, the following steps were executed: 1) if only one SOS was documented, the SOS was referred to its corresponding growing season; 2) if there was more than one SOS and the growth cycle intensity was also greater than 1.01, the SOS nearest to the occurrence of the minimum NDVI was assigned as the beginning of the first

1: We found that for some pixels, they showed more than one SOS but the growth cycle intensity for the period of 2001-2010 was less than or equal to 1.0, due to irregular rainfall or other unexpected events. 
growing cycle and the other SOS was identified as the second cycle (Fig. 2). There was no major instance of three or more growing cycles in Africa.

The GSI was then derived by integrating the NDVI profile curve over the LOS. For those pixels with one more growth cycles per year, each cycle's GSI was weighted by growth cycle intensity and then were summed (if there was no specific state, the GSI here referred to the sum value for all cycles). To eliminate the effects of climate variation, for example extreme events (Lobell 2013), we applied the LNS method on the 2001-2010 average GSI map. The temporal and spatial coefficients of variation (CVt and CVs, respectively) were produced respectively. The CVs was derived from the 10-year average GSI map.

\subsubsection{Relationship of cereal equivalent production and growing season NDVI integral}

The GSI was regarded as a proxy for productivity in terms of NPP (Mkhabela and Mashinini 2005), from which the main sources of food were derived. All the pixels' GSI values were weighted by the appropriate cropland ratio and summed per country/province per year. Subsequently, the relationship between CE and GSI was estimated using observations from the country-level or provincial level in three ways:

$$
\begin{aligned}
& \text { Linear Form: CE }=\mathrm{a} * \mathrm{GSI}+\mathrm{c}+\varepsilon \\
& \text { Exponential Form: } C E=\mathrm{e}^{\mathrm{a} * \ln (G S I)+\mathrm{b}+\varepsilon} \\
& \qquad \text { Or in Log Form: } \ln (\mathrm{CE})=\mathrm{a} * \ln (\mathrm{GSI})+\mathrm{b}+\varepsilon
\end{aligned}
$$

Binomial Form: $\mathrm{CE}=\mathrm{a} * \mathrm{GSI}^{2}+\mathrm{b} * \mathrm{GSI}+\mathrm{c}+\varepsilon$

where a, b, c were coefficients; CE was aggregated Cereal Equivalent; GSI was growing season NDVI integral; $\varepsilon$ was an error term. The the relationships in Eq. 1 and Eq. 3 were estimated with $(c \neq 0)$ and without $(c=0)$ an intercept.

Training relationship of GSI and CE production was executed in two steps. First, statistical analysis was performed on the three forms of CE production models of GSI. All models were trained by four observation data pools: (i) each country's provincial data; (ii) all country's provincial data; (iii) all country's national data and (iv) all provincial and national data. In this procedure, the performances of each of three models were tested along with the reliability of the relationship between CE production and GSI on different spatial scales. Subsequently, to test the robustness of these models, we used leave-one-year-out and 10-fold cross-validation.

\subsubsection{Estimation of currently attainable potential yield gap}

Firstly, we map the CAYgap by LNS method (Prince et al. 2009). Then the CAYgap was converted to CE-measured CAYgap (unit is tonnes/100 ha) by best performed CE-GSI model. The CAYpotential was value at the $50^{\text {th }}, 75^{\text {th }}$, and $90^{\text {th }}$ percentiles of the frequency distribution of the 10 year average GSI map for each agro-climatic zone (descripted as $50^{\text {th }}, 7^{\text {th }}$, and $90^{\text {th }}$ percentile scenarios). The $90^{\text {th }}$ percentile was an arbitrary cutoff as the upper boundary to exclude outlier values. The difference between the 10-year average GSI and the CAYpotential was the CAYgap. This procedure assumed that cropland having a CAYgap value could improve its productivity to the optimized level by adopting corresponding agricultural management that was undertaken in the same zone.

To validate the rationality of the results, two other independent sources of crop model estimated potential yield were chosen: (i) the GAEZ v4.0 model outputs of high-input level potential yield at year 2010 (Fischer et al., 2012); and (ii) the maize potential yield modeled by Christian Folberth (2013). These two sources were used to evaluate the CAPpotential. It is important to mention that these sources were not used to validate the quantitative precision of results but only their quality. Since the potential yield estimated by crop models could be regarded as agronomical potential yield and as maximum yield ceilings for other studies (van Wart et al. 2013), the assumption of this validation was that our potential production gaps should lower than those from crop models. In the comparison, the potential yields of 18 major crops from the GAEZ v4.0 model were weighted by 2010 crop harvested 
areas and aggregated into cereal equivalent potential production. A comparison was performed

\section{Results}

\subsection{Performance of growing season NDVI integral}

between the ratio of actual CE production to CAPpotential (actual achievement ratio) at the $90^{\text {th }}$ percentile scenario in this study (CAP_LNS) and the corresponding actual achievement ratios under $90 \%, 70 \%$, and $50 \%$ of GAEZ high input potential production scenarios (denoted as GAEZ_HIPP50, GAEZ_HIPP70, and GAEZ_HIPP90). Only 43 countries in sub-Saharan Africa were considered. As maize was one of the most important and most widely cultivated cereal crop in Africa, we also calculated the ratio of actual maize production to modeled maize potential production of Folberth in 2000 (base year 1997-2003) (denoted as Folberth_maize), and the ratio of actual maize production to $90 \%$ of GAEZ high input maize potential production in 2010 (denoted as GAEZ_maize). Using actual achievement ratio makes crop model estimated potential productions and CAPpotential comparable.

\subsubsection{Assessment of capacity of mitigating energy shortages}

To assess each countries' capacity of mitigating its energy shortages, we calculated additional population whose energy requirement could be met by the currently attainable production gap. We used the average dietary energy requirement (ADER) as a reference standard of a person's daily energy requirement. The depth of the food deficit of each country was used to adjust the amount of currently attainable potential production before calculating the number of additional populations. The depth of the food deficit indicated how many calories would be needed to eliminate the undernourishment from their status. The calculation steps were as follow. Firstly, all the CEmeasured CAYgap were upscaled to the national scale. Secondly, the CE production gaps in weight units were converted to values in energy units by conversion factors. Thirdly, the energy required to cover up the depth of food deficit for each country were subtracted from CE production gaps. And finally, by dividing the remaining production gaps by each countries' ADER and the days in a year, the number of additional population for each country under different percentile scenarios could be obtained:

$$
\text { POP }_{\text {mitigate }}=\frac{\left(\sum \mathrm{f}_{\mathrm{CE}-\mathrm{GSI}}(\mathrm{CAYgap})\right) * \text { ConversionFactor-depthDeficit } * \text { POP }}{\text { ADER } * 365}
$$

$\mathrm{POP}_{\text {mitigate }}$ was the additional population; $\mathrm{f}_{\mathrm{CE}-\mathrm{NDVI}}$ was the CE-GSI model (weight unit), $\sum \mathrm{f}_{\mathrm{CE}-\mathrm{NDVI}}$ (CAYgap) was upscaling pixel-level CE-measured CAYgap to production gap on countrylevel (weight unit); ConversionFactor converted production gap in weight units to energy units (kcal/100g), depthDeficit was the depth of food deficit, and POP was each countries' population.

The weight-energy conversion factor considered all kinds of cereal products. Five-year average (2005-2010) of nine cereal crop production ratios to total cereal production in Africa (wheat, rice, barley, maize, rye, oats, millet, sorghum and other cereal crops) were used to weight each crop type's weight-energy conversion factor. The conversion factors for each cereal crop product were from Kastner's work (2012). Population data was for 2010. There were five countries having no ADER data: Burundi, Democratic Republic of Congo, Equatorial Guinea, Eritrea and Libya. Therefore, results only covered 43 countries. The 2009-2011 FAO undernourishment ratio was chosen as the reference for measuring each countries' energy demand-supply imbalance. It focused on food energy supply aspect (Cafiero and Gennari 2011) and could be regarded as a synonym for hunger, measuring the shortage of energy (FAO et al. 2016).

The mean and trend of GSI are presented in Fig. 3. In general, GSI displays a strong spatial variation range, corresponding to the distribution of annual total precipitation (Fig. 3A). Nonetheless, the CVs of GSI varies with zones, and zones those are extremely hot and arid, extremely hot and xeric, and extremely hot and moist show relatively higher heterogeneity $(>0.3)$ (Table 3 in Appendix 1). 


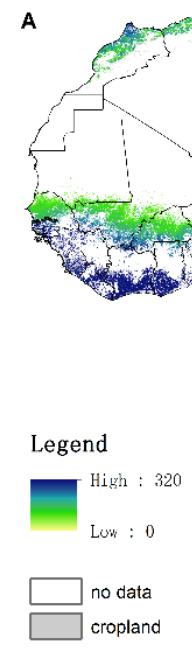
at the $90 \%$ level. statistics (Table 1).

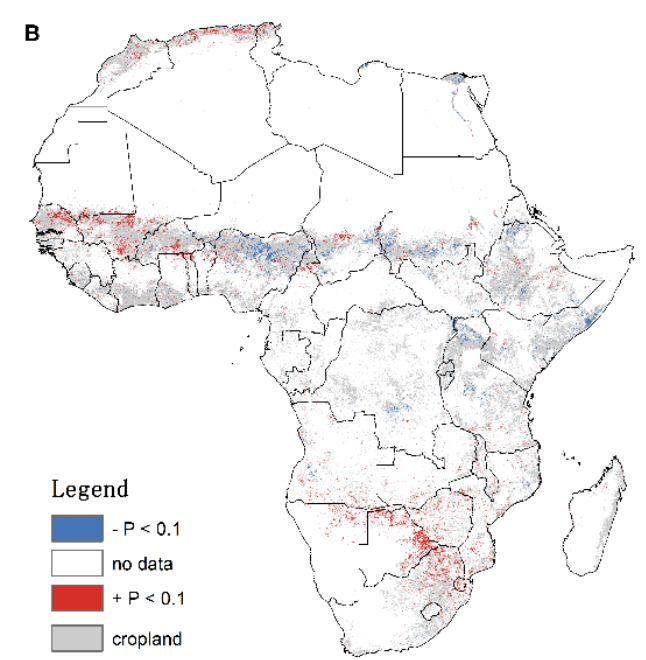

$\AA^{N}$

Fig. 3 (A): mean of GSI value; (B): trend of GSI value. Blue or red pixels' trend passed significant test

There is a clear distribution of significant positive and negative trends. Between Senegal and Benin, a large area of positive trend is observed. The area from Nigeria to Ethiopia shows mixed patterns with relatively more negative trends. Northern Africa, which mainly refers to Morocco, Algeria and Tunisia, show significant increasing trends. Increasing pattern is also observed in southern Africa. These trends can be interpreted as a recovery from the 2001-2002 droughts in southern Africa, Tunisia, and Algeria (Rojas et al. 2011). Significant negative trends occur in the areas near the Nile River, Uganda, Somalia, parts of central Africa and the western part of Tanzania, which all have sequentially suffered different degrees of drought since 2005 (drought in Central Africa was recorded approximately at 2005, and severe drought swept over East Africa from 2007 to 2009; Masih et al. 2014). These temporal fluctuations reflected, to a certain extent, the sensitivity of African cropland to extremely events.

\subsection{Modeling and validating the CE-GSI model}

Trained by observation data pools, the relationship between CE production and GSI is significant on different spatial scale level and in different form. Eight out of ten countries have a significant relationship on the provincial level (sig. test, $\mathrm{P}<0.001$; Table 4 in Appendix 2). According to goodness of fit statistics, GSI could explain greater variation of CE production at the country level (Adjusted $\mathrm{R}^{2}$ and F-statistic) than at the provincial level (Table 5 and 6 in Appendix 2). Furthermore, when models are trained by all provincial and national observations, the statistical fits are slightly improved in the coefficient of determination (adjusted $\mathrm{R}^{2}$ ), but particularly noticeable in the F-

Table 1. Fit statistics of estimations of CE production against GSI in three forms, with or without constant terms. Models are trained by all provincial and national observations from 2001-2010. The estimation of currently attainable potential yield uses the model underlined.

\begin{tabular}{|c|c|c|c|c|}
\hline & Statistic Models ${ }^{2}$ & $\begin{array}{l}\text { Adjusted } \\
\text { R-squared }\end{array}$ & $\begin{array}{l}\text { Prob. } \\
\text { (F-statistic) }\end{array}$ & $\begin{array}{l}\text { Durbin- } \\
\text { Watson stat }\end{array}$ \\
\hline Linear & $Y=1.2979 * X-411955$ & 0.6703 & $<0.0001$ & 0.7871 \\
\hline Model & $\underline{Y}=1.2569^{*} \mathrm{X}$ & 0.6677 & $<0.0001$ & 0.7811 \\
\hline $\begin{array}{l}\text { Exponential } \\
\text { Model }\end{array}$ & $\mathrm{LN}(\mathrm{Y})=0.6736^{*} \mathrm{LN}(\mathrm{X})+4.5609$ & 0.6533 & $<0.0001$ & 1.6948 \\
\hline
\end{tabular}




\begin{tabular}{lllll} 
Binomial & $\mathrm{Y}=(6.51 \mathrm{E}-08)^{*} \mathrm{X}^{2}+0.0388^{*} \mathrm{X}$ & 0.8091 & $<0.0001$ & 1.3021 \\
Model & $+1001255^{1}$ & & & \\
& $\mathrm{Y}=(5.60 \mathrm{E}-08)^{*} \mathrm{X}^{2}+0.294^{*} \mathrm{X}$ & 0.7956 & $<0.0001$ & 1.2197 \\
\hline
\end{tabular}

2. all models were trained by 1060 observations.

The three forms of models perform somewhat differently. The results of linear and exponential forms show a better fit than the binomial form for each country (Table 4 in Appendix 2). Trained by provincial or national observations, the binomial form performs better than the other two forms (Table 5 and 6 in Appendix 2). However, when excluding the 4 observations from the Oromia province of Ethiopia, or the 10 observations from Nigeria, the binomial form's goodness of fit get worse (adjusted $\mathrm{R}^{2}$ decreased from $\sim 0.55$ and $\sim 0.78$ down to $\sim 0.32$ and 0.51 , respectively). In both cases, those observations have remarkably larger CE production and GSI values than others. Furthermore, there are no statistically significant differences in linear and binomial models with or without constant term (Table 1, Table 5 and 6 in Appendix 2). However, models without constant term have more properly physical significance in this study.

The results of the 10-fold and leave-one-year-out cross-validations presented in Table 2 suggest that the exponential form has poor predictive ability. The binomial form performs better than the linear form in both validations, but its performance is weaker than the linear one when excluding Nigerian observations (Table 7 in Appendix 2). In summary, binomial form is more sensitive to extremely observation than linear form. Therefore, a single linear model without constant term trained by all provincial and national observations is used in this study to calculate the CAYpotential and CAPpotential (underlined model in Table 1; the scatter plot of all provincial and national CE 399 production and their corresponding aggregated GSI is showed in Figure 7 in Appendix 2).

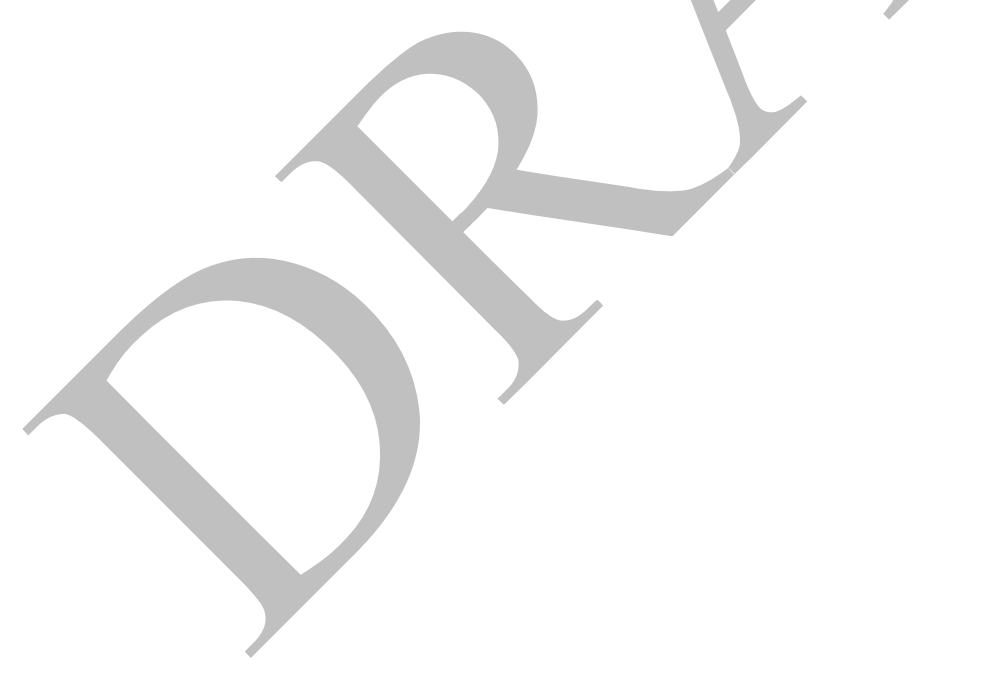


Table 2. Cross-validated coefficients of comparison between predicted and actual CE production. 10-fold cross validation is applied on two observations: 1) all provincial and national observations; 2) all national observations. Leave-one-year-out cross validation is applied on all national observations.

\begin{tabular}{|c|c|c|c|c|c|c|c|}
\hline & & \multicolumn{2}{|c|}{ Linear Model } & \multicolumn{2}{|l|}{ Power Model } & \multicolumn{2}{|l|}{ Binominal Model } \\
\hline \multirow{3}{*}{$\begin{array}{l}\text { 10-fold cross } \\
\text { validation }\end{array}$} & & Model & $\mathbf{R}^{2}$ & Model & $\mathbf{R}^{2}$ & Model & $\mathbf{R}^{2}$ \\
\hline & \multirow{2}{*}{\multicolumn{2}{|c|}{$\begin{array}{l}\text { Provincial, National Obs. } \\
\text { National Obs. }\end{array}$}} & 0.656 & & & & 0.788 \\
\hline & & & 0.5803 & & 53 & & 0.6874 \\
\hline \multirow{10}{*}{$\begin{array}{l}\text { Leave-one-year-out } \\
\text { cross validation } \\
\text { (All National } \\
\text { Observations) }\end{array}$} & 2001 & $Y=1.2104^{*} X$ & 0.5894 & $Y=28.6160^{*} X^{0.7616}$ & 0.4057 & $Y=(5.24 \mathrm{E}-08)^{*} X^{2}+0.2463^{*} X$ & 0.6351 \\
\hline & 2002 & $Y=1.2015^{*} X$ & 0.5857 & $Y=30.2217^{*} X^{0.7585}$ & 0.362 & $Y=(5.06 \mathrm{E}-08)^{*} X^{2}+0.2628^{*} X$ & 0.7121 \\
\hline & 2003 & $Y=1.1983^{*} X$ & 0.6236 & $Y=30.0721^{*} X^{0.7581}$ & 0.3565 & $Y=(5.11 E-08)^{*} X^{2}+0.2556^{*} X$ & 0.745 \\
\hline & 2004 & $Y=1.1949^{*} X$ & 0.5803 & $Y=30.2878^{*} X^{0.7576}$ & 0.3197 & $Y=(4.99 \mathrm{E}-08)^{*} \mathrm{X}^{2}+0.2721^{*} X$ & 0.7221 \\
\hline & 2005 & $Y=1.1776^{*} X$ & 0.6486 & $Y=29.4819^{*} X^{0.7588}$ & 0.3142 & $Y=(4.99 E-08)^{*} X^{2}+0.2590^{*} X$ & 0.7735 \\
\hline & 2006 & $Y=1.1903^{*} X$ & 0.5275 & $Y=28.2244^{*} X^{0.7618}$ & 0.2732 & $Y=(4.99 E-08)^{*} X^{2}+0.2745^{*} X$ & 0.6393 \\
\hline & 2007 & $Y=1.1887^{*} X$ & 0.5934 & $Y=28.3168^{*} X^{0.7620}$ & 0.3122 & $Y=(4.97 \mathrm{E}-08)^{*} \mathrm{X}^{2}+0.2711^{*} \mathrm{X}$ & 0.7264 \\
\hline & 2008 & $Y=1.1811^{*} X$ & 0.5487 & $Y=33.8866^{*} X^{0.7495}$ & 0.2536 & $Y=(5.01 E-08)^{*} X^{2}+0.2534^{*} X$ & 0.6447 \\
\hline & 2009 & $\mathrm{Y}=1.1821^{*} \mathrm{X}$ & 0.6542 & $\mathrm{Y}=33.8465^{*} \mathrm{X}^{0.7488}$ & 0.2861 & $Y=(5.11 E-08)^{*} X^{2}+0.2304^{*} X$ & 0.7371 \\
\hline & 2010 & $\mathrm{Y}=1.1717^{*} \mathrm{X}$ & 0.5983 & $Y=29.2526^{*} X^{0.7582}$ & 0.2485 & $Y=(5.07 \mathrm{E}-08)^{*} X^{2}+0.2337^{*} X$ & 0.6812 \\
\hline
\end{tabular}




\subsection{Currently attainable yield-gap and production}

The distribution of CAYgap (Fig. 4A, B, and C) is similar to the ratio of CAYgap to CAYpotential (Fig. 4D, E, F). The CAYgap areas mainly appear at the north of a transect from Senegal to Ethiopia, followed by the cropland region around the Horn of Africa (Fig. 4). The spatial distribution of CAYgap and the ratio of CAYgap to CAYpotential at three percentile scenarios are also similar, respectively, and present a reasonable pattern that the $90^{\text {th }}$ percentile scenario has higher CAYgap value and corresponding larger yield improving space (Fig. 4C and 4F).
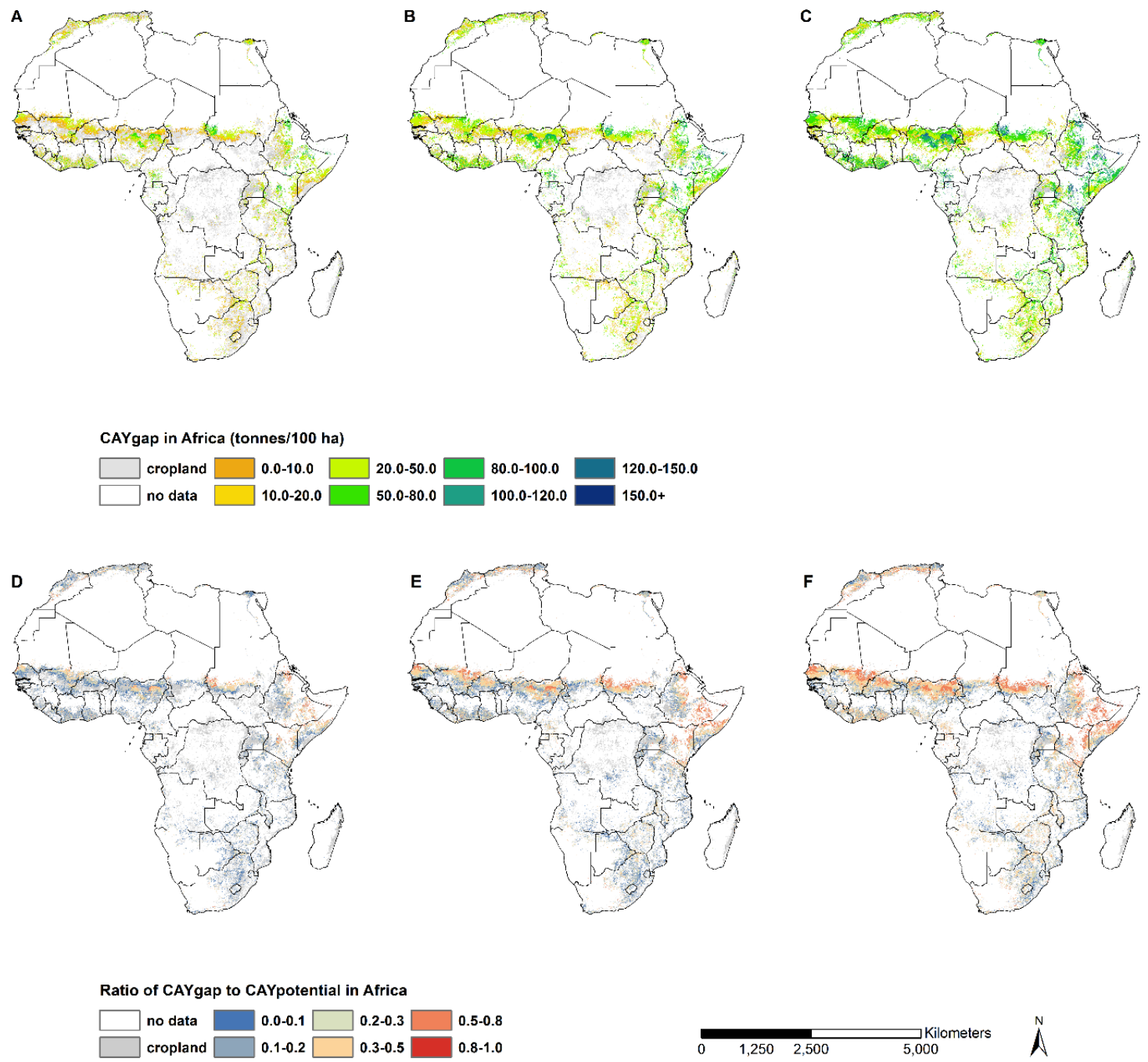

Fig. 4 CAYgap (tonnes/100 ha) in Africa at (A) 50th-percentile, (B) $75^{\text {th }}$-percentile, (C) $90^{\text {th }}$-percentile scenario. Ratio of CAYgap to CAYpotential in Africa at (D) $50^{\text {th }}$-percentile, (E) $75^{\text {th }}$-percentile, (F) $90^{\text {th }}$ percentile scenario.

Upscaling CAYgap into country level, results are not optimistic (Fig. 5). Only 10 out of 48 countries could potentially double or further improve their CE production at the $90^{\text {th }}$ scenario, while 7 out of those 10 countries rank in the top 10 of least actual CE production (Fig. 5). Improving the CE production of these 7 countries could help mitigate their internal food insecurity, but would contribute little to the continental situation by trade. Countries on the transect also have the capacity to double (or thereabouts) their CE production at the $90^{\text {th }}$ scenario, and most of them already have 
high actual CE production (except Somalia), especially Sudan (former) and Ethiopia. For the rest countries, 23 countries could only add less than a quarter of their actual CE production even under the $90^{\text {th }}$ percentile scenario. Due to lacking valid NDVI values, the currently attainable CE production of Madagascar and DR. Congo are very low. Similarly, Egypt also has low currently attainable CE production because of lacking comparatively data on irrigated cropland.

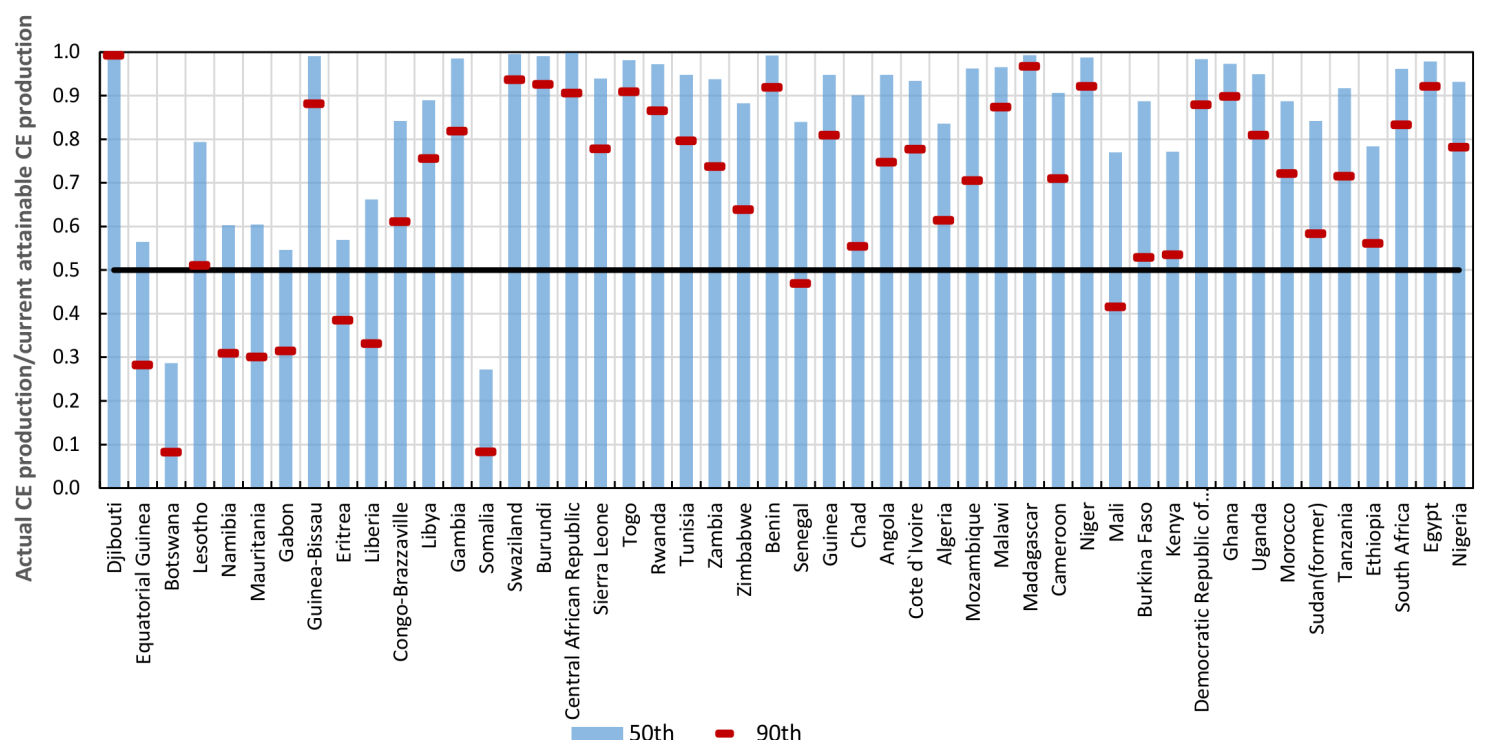

Fig. 5 Ratios of actual CE production to currently attainable CE production for each country. The light blue histogram represents the ratio for the $50^{\text {th }}$ percentile scenario while the red short line represents the $90^{\text {th }}$ percentiles scenario. Black line represents the position where ratio equals 0.5 , as a reference. All countries are sorted from left to right by their total actual CE production.

Comparing the pixel-level result (Fig. 4) to the upscaled aggregated country-level result (Fig. 5), many countries have a large area of high CAYgap hotspots but have low country-level potential production gaps. This is because places with high CAYgap may have very low actual yields and low CAYpotential. For example, in Nigeria, almost all places in Katsina and Yobe provinces have ratio of CAYgap to CAYpotential larger than 0.5, while places in Niger and Taraba provinces have ratio under 0.3 (Figure 3f). Yet in 2010, the actual CE production of the latter two provinces is 2.3 times than that of the former two, as well as the actual achievement ratio of this country is more than 0.78 . Correspondingly, hotspots of high CAYgap occurring at high actual yield region would result in relatively lower actual achievement ratios at country-level, such as Ethiopia and Senegal.

\subsection{Additional population fed by currently attainable production gap}

Parts of countries have negative values under some scenarios, implying that they couldn't make up for the current food energy deficit by their currently attainable production gaps. Results show that there are still 3 countries who have negative values under $90^{\text {th }}$ percentile scenario, namely Rwanda, Madagascar and Djibouti. Under the 50th percentile scenario, this number reached up to 19 (Fig. 6). 11 countries could additionally meet more than half of their 2010 population's energy requirement, and 5 countries even could feed a number more than their 2010 population under $90^{\text {th }}$ percentile scenario. However, only Gabon has the capacity of meeting the energy requirement of a half more of its 2010 population under the $50^{\text {th }}$ percentile scenario.

There are some very undernourished countries having high capacities to mitigate energy shortages, such as Chad, Namibia or Liberia. However, some countries have poor capacities, such as Central Africa, Rwanda and so on. For countries such as Zambia, Benin or Mozambique, they do not have the capacity to make up for their energy shortages under $50^{\text {th }}$ percentile scenario, but do have at $75^{\text {th }}$ or higher percentile scenario. Some countries, such as Mali or Gabon, not only could 
additionally feed more population, but their FAO undernourishment values indicate that they do not

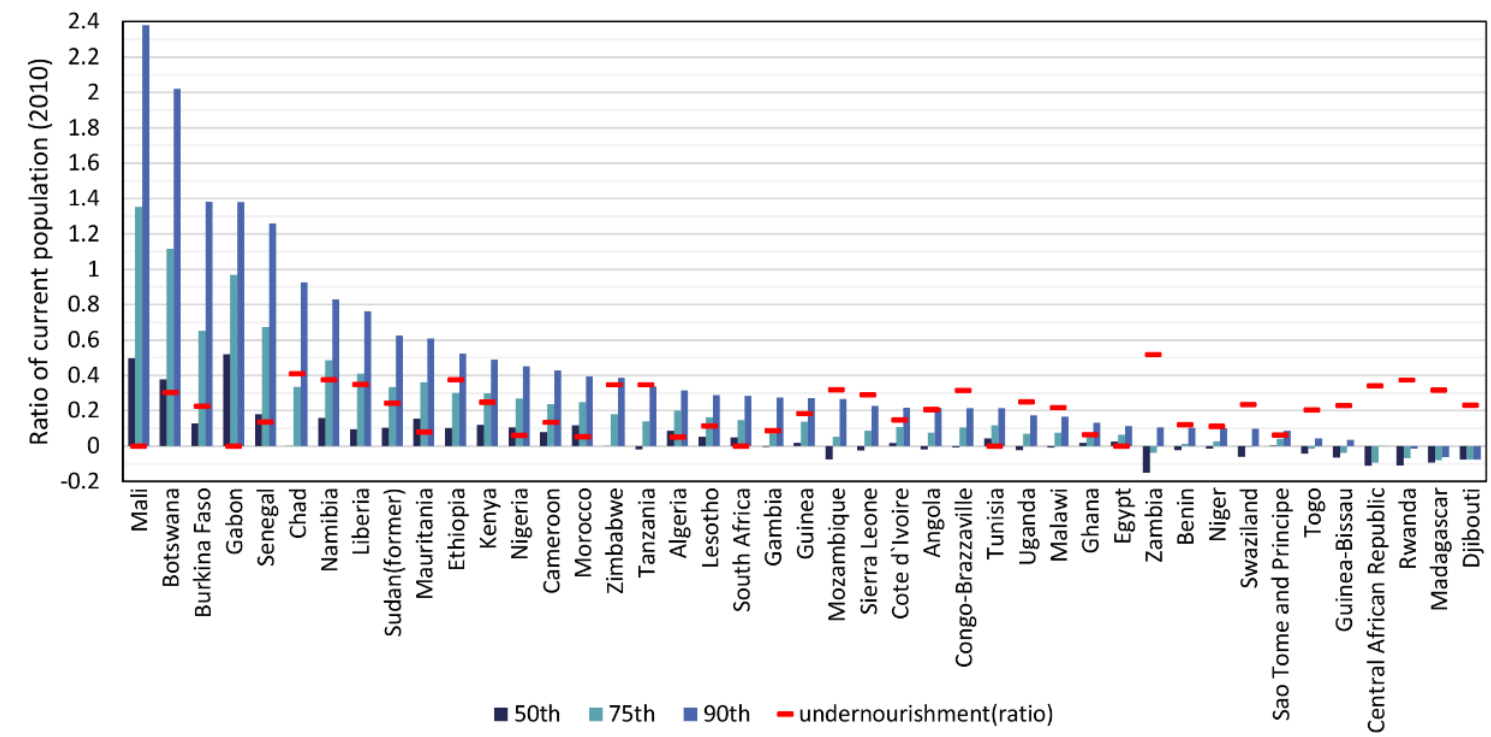

Fig. 6 Ratio of additional population to 2010 population at different scenarios for each country. Dark

\section{Discussion} green bars represent ratios of additional population to 2010 population when production reach to $50^{\text {th }}$ percentile scenario CE production; blue-green bars represent ratios of additional population to 2010 population when production reach to $75^{\text {th }}$ percentile scenario CE production; blue bars represent ratios of additional population to 2010 population when production reach to $90^{\text {th }}$ percentile scenario CE production; red short lines represent the ratio of undernourished to total population at 2009-2011 (FAO undernourishment), respectively. All countries are sorted from left to right by ratios of additional population to 2010 population at $90^{\text {th }}$ percentile scenario, from largest to smallest.

4.1. Comparison between currently attainable potential production to crop-modelled potential production
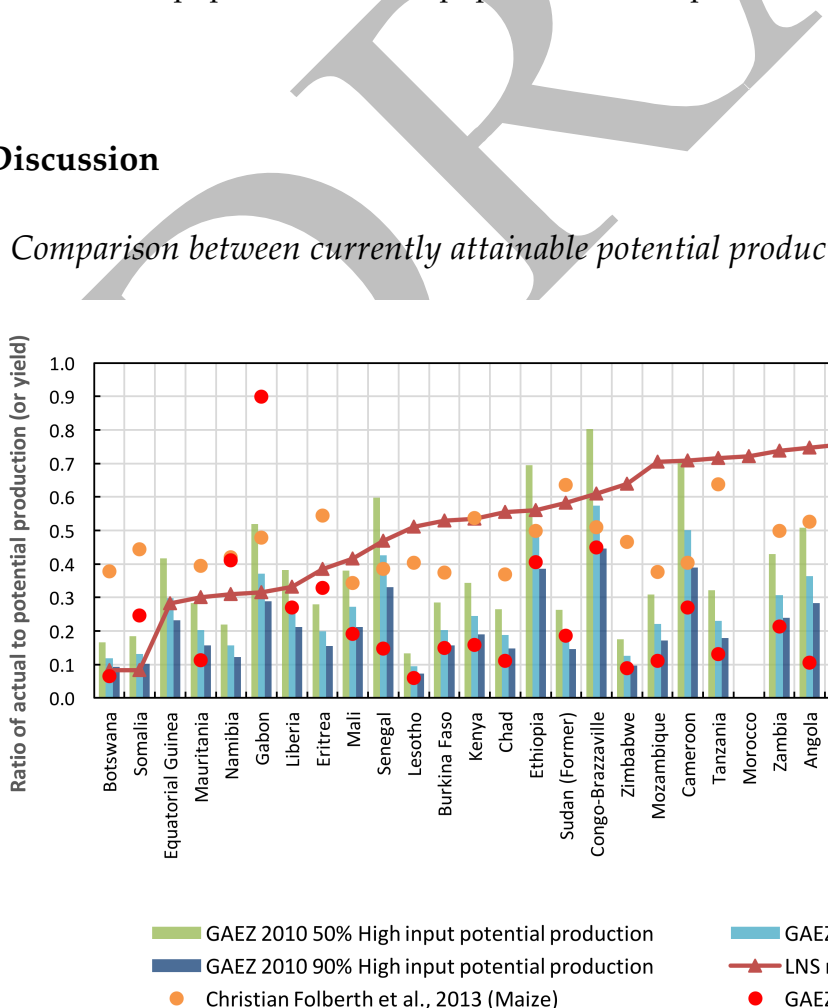

GAEZ 2010 90\% High input potential production

GAEZ 2010 70\% High input potential production

-LNS method 90th percentile potential production

- GAEZ 2010 High input potential production (Maize) 
Fig. 7 Comparison between ratio of actual CE production to currently attainable CE production at the 90th percentile scenario in this study (CAP_LNS) and 1) the corresponding actual achievement ratios calculated using respectively $90 \%, 70 \%$, and $50 \%$ of GAEZ high input potential production (denoted as GAEZ_HIPP50, GAEZ_HIPP70, and GAEZ_HIPP90), 2) ratio of actual maize production to modelled maize potential production of Folberth at 2000 (base year 1997--2003) [43] (denoted as Folberth_maize), and 3) ratio of actual maize production to $90 \%$ of GAEZ high input potential production at 2010 (denoted as GAEZ_maize). Only 43 countries in sub-Saharan Africa were considered.

In this case study, the CAPpotential estimated by LNS approach was much lower than that estimated by crop models (Fig. 7). Only 8 countries have lower actual achievement ratios by CAP_LNS at the $90^{\text {th }}$ scenario compared to GAEZ_HIPP50. Similarly, the remaining countries' actual achievement ratios of CAP_LNS are higher than the ratios of Folberth_maize and the ratios of GAEZ_maize, respectively. The high actual achievement ratios of CAP_LNS imply that, currently, in most agro-climatic zones the general yield (or in other words, the CE yield) of cropland in Africa is rather low. Furthermore, there are insufficient cropland pixels depicting superior performance to place the CAYpotential near to the theoretically modeled potential yield level. This emphasizes that the LNS approach is feasible for mapping divergences in regional crop yield and quantifying the yield-gaps between actual yield and observed preferable attainable yield, rather than accurately estimating the theoretically agronomic yield-gap.

\subsection{Uncertainties, assumptions and concerns}

The accuracy of phenological metrics is important for the estimation of GSI. Compared to other studies (Brown et al. 2012; Vrieling et al. 2011; Vrieling et al. 2013), the phenological metric values calculated in this study are reasonable. Considering the fact that the occurrence and duration of the rainy season directly affects the phenology of the rain-fed farming system, and the fact that germination period of many crops is very sensitive to rainfall, it is necessary to take into consideration of the precipitation phenology in future studies (Funk and Budde 2009).

It is hard to verify the reliability of agricultural statistics reported by relevant departments, especially in Africa. Comparing crops of cereal and starchy roots categories from CountrySTAT to those from FAOSTAT, many countries have different crop production values in these two data source like Nigeria and Zambia. Though there are many arguments on the poor quality of FAOSTAT (Choudhury and Headey 2017), the characteristics of universality, comparability, long-time records and annual update for most countries make FAOSTAT still the most widely used and available agricultural statistics, especially for Africa. Cropland data could also bring uncertainty into the result. For example, there are many disagreements between GlobCover2009 and the IIASA-IFPRI cropland ratio product (Fritz et al. 2015). Since the quality of cropland data affects the quantity of provincial or national aggregated GSI and the goodness of model fitting, a comparison and validation of cropland data in Africa is very important (See et al. 2015; Waldner et al. 2015).

Our analysis does not account for several factors that might be important for future agricultural production. First, we assume that the ratio of harvested NPP as crop matters to the NPP of the whole crop plant is constant during the period 2001-2010 for each crop plant and that they are the same across all countries. However, the harvested ratio of each plant could improve along with the application of advanced agricultural technologies. Second, due to lacking spatially temporal data of cropping intensity, we do not consider the contribution of divergence of cropping intensity to the CAYgap.

Third, we do not consider shares of different crops to GSI or CAYpotential. In many parts of rural Africa, food is predominantly derived from local NPP, due to many poor communities lacking access to markets. Some studies have used proxy of NPP, for instance the GSI, as a proxy for yield (Becker-Reshef et al. 2010; Mkhabela et al. 2011). These studies are primarily based on fitting a regression model between NPP proxy and crop yield data for specific crops, as opposed to this application over a large range of crop categories. Therefore, the yield in the present study represents a generalized NPP yield of cropland, rather than yield of individual crops. It is suggested that the 
ability to cultivate crops in regions with high potential productivity is not only determined by the suitability of the agro-climate, but also by food prices and market requirements, which hamper determination of the planned crop type for each pixel.

The rationale of representativeness of maximum GSI (CAYpotential) is one of the core assumptions for this method. Several points should be addressed. In contrast to crops grown without irrigation or without fertilizer application, where productivity is often less than that of native vegetation growth (Lobell et al. 2009), high-input agriculture (for example, in North America and Europe) consistently displays higher annual NPP than the natural vegetation in cropland areas (DeFries et al. 1999). The most productive agricultural areas are usually located in well managed, fertilized, and possibly irrigated areas, and the selection of these as the estimator of potential NPP is an indicator of maximum productivity of each zone (Prince et al. 2009). Since the current study has zoned cropland into agro-climatic homogenous zones, the maximum NPP proxy in each zone is more likely to result from comparatively constant improved crop management, and it could be regarded as a currently attainable potential yield for each region. However, high input and output agriculture normally occurs in developed countries rather than in Africa. Since the current preliminary attempt focused only on the African continent, the yield values observed in the best performing grid-cells in each agro-climatic zone may have been lower than the global maximum yield, let alone values estimated by well-adapted crop models (Fig. 7). In other words, there calls further global scale studies to assess the spatial and temporal dynamics of gaps of agricultural productivity from African countries to the global best practices.

\subsection{Concerns about results}

Theoretically, if improve each countries' productivity to the zonal optimal level, and the additional production distribute equally to all population, $24 \sim 40$ out of all countries have the capacity to mitigate their current energy shortages independently. In reality, agricultural production is not only directly used for household consumption, most of them would convert to food products by multi-level processing, or be used as seeds, industrial raw materials, or more important be used as feed grain in animal husbandry. During those processes, many energies would be lost. Taking into consideration of energies obtained from grazing, nomadic and fisheries rather than cropland, and the potential energies from the gap between zonal optimal level and theoretically modelled level (Fig. 7), it implies that there is of great potential for African countries to solve the food security problems by their cultivated cropland.

We argue that our study addresses only adopting observed best cultivating practice opportunity to increase production. It is difficult to conclude that those countries with a higher ratio of CAYgap to CAYpotential have a higher potential to contribute to food security or to the mitigation of undernourishment. Low production is not only caused by the ecosystem but also by social and economic issues. For example, of the high yield-gap ratio countries, Liberia experiences social war and conflict during the study period (Owadi et al. 2010), Mauritania experiences several years of drought (Daniel 2011), and Namibia has the highest poverty levels (Frayne 2005). Therefore, many socio-economic and institutional factors need to be attuned to allow for production increases, and it is these factors which cause the yield divergences in each homogeneous zone across the African continents.

Increasing crop productivity may cause problems for the sustainability of ecological systems, since improvement in productivity would translate into environmental challenges or even into the intensification of the current issues (Chen and Li 2010; Hiernaux et al. 2009; Zaka and Erb 2009). However, this is a critical but at the same time necessary step to achieving food security. Given the increasing concerns associated with global food security projections, and rapid population growth seen especially in Africa, the targeting of regions with a lower than optimum crop yield is of paramount importance if a food crisis is to be avoided (Dawson et al. 2016). A greater consideration of the trade-offs between balancing the needs of humans and the ecosystem (Zhang et al. 2015), combined with a plan for sustainable improvement of crop productivity, is undoubtedly needed. 
Identifying and quantifying hotspot of yield divergence is an initial but essential step towards mitigating food insecurity by observing and adopting best regional agricultural practices. Our study demonstrates the feasibility of the method that applies satellite-derived indicators for the maximum yield achieved to quantify and map the current cropland yield divergence and corresponding yieldgaps by Local NPP Scaling method. Furthermore, this method could be applied on different spatial level from regional to global scale with reasonable homogeneous zone scheme. And this can help inform decision making at various levels, from micro- to macro- level policies.

Increasing yield productivity to meet food energy requirement is not only a regional problem in Africa, but also a global issue. This study leads to identify agricultural management implications and adaptation strategies for both Africa and the globe.

1. It is socio-economic and institutional factors rather than bio-geophysical factors that contributed most to hunger prevalence.

The gaps between reality of hunger and results of capacity from our study emphasize the importance to figure out what and how socio-economic and institutional factors cause yield divergence across agro-climatic zones. Clarifying this causal mechanism happened on study region help people derive and implement more practical policies on agricultural development and food security improvement.

2. Strengthening the resilience of individual/household food access is of essential importance for ensuring food security.

Large uncertainty exists between adequate supply at the national level and demand satisfaction at the household level. Currently, many studies (Burchi and De Muro 2016; Leroy et al. 2015; Campbell et al. 2016) point out the importance of food access in ensuring food security from household to national level. According to the definition of food security, food access is directly determined by household or individual income level, physical capacity of accessing food, and rights. And these factors interact with upper stream determinants such as national policies, trends of globalization, and changes in economic structures. For example, global food trade shocks, food price volatility, and energy policies of other countries may cause great impact on food access and food availability of low-income countries. Additionally, different studies also have shown that climate change might cause significant impact on food access (Schmidhuber and Tubiello, 2007; Wheeler and von Braun, 2013). All those factors characterize the resilience and vulnerability of food access. Therefore, it's important to clarify what factors are at play and how they impact on individual/household food access and food availability in order to make effective resiliencestrengthening policies. Beyond the food availability on national level, more concerns should be paid to understand how those factors of food access would impact the future food security, and how to make national food availability favors households and individuals.

3. Equipping agricultural systems with multi-spatial and temporal scale monitoring systems on dynamics of crop yields and yield divergence should be among the priority of development needs in less developed areas.

The monitoring systems not only contribute to the detection of less-improving hotspots, but also to providing early warning impacts of climate extremes, climate variation and climate change. Currently, several international agricultural monitoring or researching platforms are well established, such as International Maize and Wheat Improvement Center (https://www.cimmyt.org/) on improving maize and wheat yields by field studies, Global Yield Gap Atlas (http://www.yieldgap.org/) on estimating crop agronomical potential yield, and GEOGLAM Early Warning Crop Monitor (https://cropmonitor.org/) on monitoring the climatic impact on yield. However, there is still call for providing comprehensive platforms that systematically serve for less developed countries which plagued by food security.

\section{Conclusion}


Spatial cropland yield divergences in agro-climatic homogeneous zones usually imply gaps which have potential to be closed up and then improve the local productivity by adopting currently observed best cultivating practices. This work used satellite derived indicator as a proxy of the cropland productivity to reveal such spatial differences in cropland, to find the hotspots of cropland where having potential of improving productivity to currently observed optimal level, and to evaluate each countries' current potential of making up the shortages of food energy.

The results show that under the current agricultural climatic conditions, the hotspots of cropland in Africa are mainly at the Horn of Africa, as well as the transect from Senegal to the Ethiopia. Improving each countries' productivity to the zonal optimal level, $\sim 90 \%$ out of all countries have the capacity to mitigate their current energy shortages as measured by FAO undernourishment indicator, independently. After adjusted by the depth of the food deficit, 11 countries could feed more then half of the current population according to the average dietary energy requirement. And, for example Mali and Gabon, some countries not only have a high improving space of production, but the FAO undernourishment indicator show that these countries almost have no energy shortage, implying a great optimistic future.

Compared to modelled potential production, the relatively low attainable potential production from our study implies that current cropland yields in most agro-climatic zones of Africa are depressed. In the view of the large difference between potential production achieved by this study and the one by crop model, the current cropland of each African country have further potential to improve their production.

The present study demonstrates the feasibility of applying satellite-derived indicators for the maximum yield achieved method to quantify and map the current cropland yield divergence by LNS method, and this method could be applied on different spatial level from regional to global scale with reasonable homogeneous zone scheme. And based on results, three global global implications and strategies are recommended: 1) It is socio-economic and institutional factors rather than biogeophysical factors that contributed most to hunger prevalence; 2) Strengthening the resilience of individual/household food access is of essential importance for ensuring food security; and 3) Equipping agricultural systems with multi-spatial and temporal scale monitoring systems on dynamics of crop yields and yield divergence should be among the priority of development needs in less developed areas.
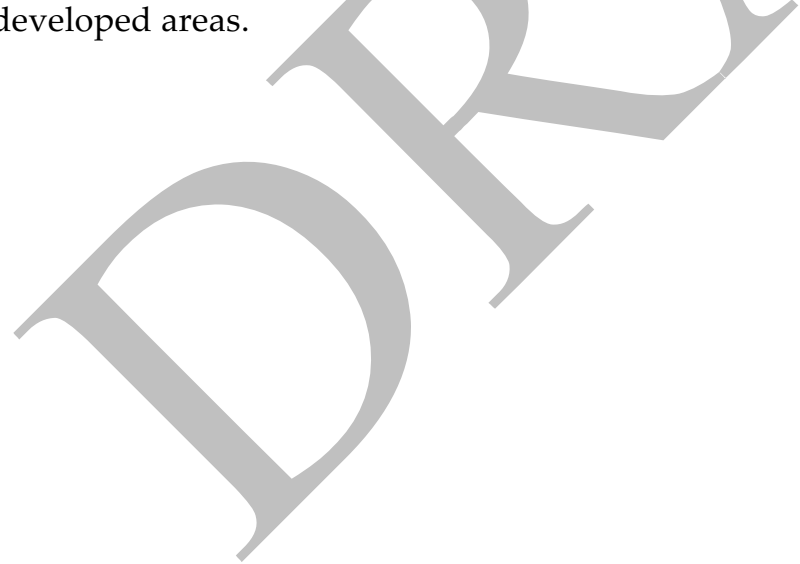
655 List of Abbreviations appeared in this study
CAYgap
CAYpotential
CAPpotential
Currently attainable potential yield gap
Currently attainable potential yield
Currently attainable potential production

EOS
GAEZ
GEnS
GlobCover 2009
GSI

HANPP

LNS

LOS

MODIS

MVC

NDVI

NPP

SOS
The end of season

Global Agro-Ecological Zones - Model

Global Environmental Stratification

GlobCover 2009 database

growing season NDVI integral

Human appropriation of the vegetation net primary production

Local NPP Scaling

The length of season

The Moderate-resolution Imaging Spectroradiometer

The Maximum Value Composite

Normalized Difference Vegetation Index

The vegetation net primary production

The start of season

\section{References}

Atzberger C (2013) Advances in remote sensing of agriculture: Context description, existing operational monitoring systems and major information needs. Remote Sens. 5:949-981

Becker-Reshef I, Vermote E, Lindeman M, Justice C (2010) A generalized regression-based model for forecasting winter wheat yields in Kansas and Ukraine using MODIS data. Remote Sens Environ 114:1312-1323. doi: 10.1016/j.rse.2010.01.010

Biradar CM, Xiao XM (2011) Quantifying the area and spatial distribution of double- and triple-cropping croplands in India with multi-temporal MODIS imagery in 2005. Int J Remote Sens 32:367-386. doi: 10.1080/01431160903464179

Bolton DK, Friedl MA (2013) Forecasting crop yield using remotely sensed vegetation indices and crop phenology metrics. Agric For Meteorol 173:74-84. doi: http://dx.doi.org/10.1016/j.agrformet.2013.01.007

Bontemps S, Defourny P, Bogaert E Van, et al (2011) GLOBCOVER 2009 Products Description and Validation Report. ESA Bull 136:53. doi: 10013/epic.39884.d016

Brown ME, de Beurs K, Vrieling A (2010) The response of African land surface phenology to large scale climate oscillations. Remote Sens Environ 114:2286-2296. doi: 10.1016/j.rse.2010.05.005

Brown ME, de Beurs KM, Marshall M (2012) Global phenological response to climate change in crop areas using satellite remote sensing of vegetation, humidity and temperature over 26 years. Remote Sens Environ 126:174-183. doi: 10.1016/j.rse.2012.08.009

Burchi F, De Muro P (2016) From food availability to nutritional capabilities: Advancing food security analysis. Food Policy 60:10-19. doi: 10.1016/j.foodpol.2015.03.008

Burke M, Lobell DB (2017) Satellite-based assessment of yield variation and its determinants in smallholder African systems. Proc Natl Acad Sci 114:2189-2194. doi: 10.1073/pnas.1616919114

Cafiero C, Gennari P (2011) The FAO indicator of the prevalence of undernourishment. In: workshop on Measuring Food Insecurity. The National Academies. Washington, DC 
Campbell BM, Vermeulen SJ, Aggarwal PK, et al (2016) Reducing risks to food security from climate change. Glob Food Sec 11:0-1. doi: 10.1016/j.gfs.2016.06.002

Chen J, Jonsson P, Tamura M, et al (2004) A simple method for reconstructing a high-quality NDVI time-series data set based on the Savitzky-Golay filter. Remote Sens Environ 91:332-344. doi: 10.1016/j.rse.2004.03.014

Chen X, Li B (2010) Global scale assessment of the relative contribution of climate and non-climate factors on annual vegetation change. Geofizika 27:37-43

Choudhury S, Headey D (2017) What drives diversification of national food supplies? A cross-country analysis. Glob. Food Sec. 15:85-93

Daniel S (2011) Land Grabbing and Potential Implications for World Food Security. In: Sustainable Agricultural development. pp 25-42

Dawson TP, Perryman AH, Osborne TM (2016) Modelling impacts of climate change on global food security. Clim Change 134:429-440. doi: 10.1007/s10584-014-1277-y

de Beurs KM, Henebry GM (2010) Spatio-Temporal Statistical Methods for Modelling Land Surface Phenology

DeFries RS, Field CB, Fung I, et al (1999) Combining satellite data and biogeochemical models to estimate global effects of human-induced land cover change on carbon emissions and primary productivity. Global Biogeochem Cycles 13:803-815. doi: 10.1029/1999gb900037

Duku C, Zwart SJ, van Bussel LGJ, Hein L (2018) Quantifying trade-offs between future yield levels, food availability and forest and woodland conservation in Benin. Sci Total Environ 610-611:1581-1589. doi: 10.1016/j.scitotenv.2017.06.115

Duncan JMA, Dash J, Atkinson PM (2015a) Elucidating the impact of temperature variability and extremes on cereal croplands through remote sensing. Glob Chang Biol 21:1541-1551. doi: 10.1111/gcb.12660

Duncan JMA, Dash J and Atkinson PM (2015b) The potential of satellite-observed crop phenology to enhance yield gap assessments in smallholder landscapes. Front. Environ. Sci. 3:56. doi: 10.3389/fenvs.2015.00056

Erb KH, Lauk C, Kastner T, et al (2016) Exploring the biophysical option space for feeding the world without deforestation. Nat Commun 7:. doi: 10.1038/ncomms11382

Erdogan HE, Pellikka PKE, Clark B (2011) Modelling the impact of land-cover change on potential soil loss in the Taita Hills, Kenya, between 1987 and 2003 using remote-sensing and geospatial data. Int J Remote Sens 32:5919-5945

FAO (2000) Technical Conversion Factors for Agricultural Commodities. FAO.

FAO (2006) Agro-MAPS. A global spatial database of subnational agricultural land-use statistics (CD-ROM). FAO L. Water Digit. Media Ser.

FAO (2017) Regional Overview of Food Security and Nutrition in Africa 2016. The challenges of building resilience to shocks and stresses. Accra.

FAO, IFAD, WFP (2016) The State of Food Insecurity in the World 2015. Meeting the 2015 international hunger targets: taking stock of uneven progress

FAO, IFAD, WFP (2017) The State of Food Insecurity in the World 2016-Building resilience for peace and food security

FAOSTAT (2017) FAOSTAT Database. In: Food Agricutural Organ. United Nations. http://faostat3.fao.org/home/E

Fischer G, Nachtergaele FO, Prieler S, et al (2012) Global Agro-Ecological Zones (GAEZ v3. 0): Model Documentation

Folberth C, Yang H, Gaiser T, et al (2013) Modeling maize yield responses to improvement in nutrient, water and cultivar inputs in sub-Saharan Africa. Agric Syst 119:22-34. doi: 10.1016/j.agsy.2013.04.002 
Frayne B (2005) Survival of the poorest: migration and food security in Namibia. Agropolis Soc Polit Environ Dimens urban Agric

Fritz S, See L, Mccallum I, et al (2015) Mapping global cropland and field size. Glob Chang Biol 21:1980-1992. doi: $10.1111 /$ gcb.12838

Funk C, Budde ME (2009) Phenologically-tuned MODIS NDVI-based production anomaly estimates for Zimbabwe. Remote Sens Environ 113:115-125. doi: 10.1016/j.rse.2008.08.015

Gaiser T, Judex M, Igué AM, et al (2011) Future productivity of fallow systems in Sub-Saharan Africa: Is the effect of demographic pressure and fallow reduction more significant than climate change? Agric For Meteorol 151:1120-1130. doi: 10.1016/j.agrformet.2011.03.015

Godfray HCJ, Beddington JR, Crute IR, et al (2010) Food Security: The Challenge of Feeding 9 Billion People. Science (80- ) 327:812-818. doi: 10.1126/science.1185383

Haberl H, Erb KH, Krausmann F, et al (2007) Quantifying and mapping the human appropriation of net primary 10.1073/pnas.0704243104

Heumann BW, Seaquist JW, Eklundh L, Jonsson P (2007) AVHRR derived phenological change in the Sahel and Soudan, Africa, 1982-2005. Remote Sens Environ 108:385-392, doi: 10.1016/j.rse.2006.11.025

Hiernaux P, Ayantunde A, Kalilou A, et al (2009) Trends in productivity of crops, fallow and rangelands in Southwest Niger: Impact of land use, management and variable rainfall. J Hydrol 375:65-77. doi: 10.1016/j.jhydrol.2009.01.032

Huang J, Wang X, Li X, et al (2013) Remotely Sensed Rice Yield Prediction Using Multi-Temporal NDVI Data Derived from NOAA's-AVHRR. PLoS One 8:. doi: 10.1371/journal.pone.0070816

Johnston M, Licker R, Foley J, et al (2011) Closing the gap: global potential for increasing biofuel production through agricultural intensification. Environ Res Lett 6:. doi: 034028 10.1088/1748-9326/6/3/034028

Kasnakoglu H FAOSTAT and CountrySTAT: Integrated Global and National Food and Agriculture Statistical Databases

Kastner T, Rivas MJI, Koch W, Nonhebel S (2012) Global changes in diets and the consequences for land requirements for food. Proc Natl Acad Sci U S A 109:6868-6872. doi: 10.1073/pnas.1117054109

Leroy JL, Ruel M, Frongillo EA, et al (2015) Measuring the food access dimension of food security: A critical review and mapping of indicators. Food Nutr Bull 36:167-195. doi: 10.1177/0379572115587274

Licker R, Johnston M, Foley JA, et al (2010) Mind the gap: how do climate and agricultural management explain the "yield gap" of croplands around the world? Glob Ecol Biogeogr 19:769-782. doi: 10.1111/j.14668238.2010.00563.x

Liu JH, Zhu WQ, Cui XF (2012) A Shape-matching Cropping Index (CI) Mapping Method to Determine Agricultural Cropland Intensities in China using MODIS Time-series Data. Photogramm Eng Remote Sensing 78:829-837

Lobell DB (2012) The use of satellite data for crop yield gap analysis. F Crop Res. doi: 10.1016/j.fcr.2012.08.008

Lobell DB (2013) The use of satellite data for crop yield gap analysis. F Crop Res 143:56-64. doi: 10.1016/j.fcr.2012.08.008

Lobell DB, Cassman KG, Field CB (2009) Crop Yield Gaps: Their Importance, Magnitudes, and Causes. In: Annual Review of Environment and Resources. pp 179-204

Luan Y, Cui X, Ferrat M (2013) Historical trends of food self-sufficiency in Africa. Food Secur 5:393-405. doi: 10.1007/s12571-013-0260-1

765 Masih I, Maskey S, Mussá FEF, Trambauer P (2014) A review of droughts on the African continent: A geospatial 
and long-term perspective. Hydrol. Earth Syst. Sci. 18:3635-3649

Mauser W, Klepper G, Zabel F, et al (2015) Global biomass production potentials exceed expected future demand without the need for cropland expansion. Nat Commun 6:. doi: 10.1038/ncomms9946

Metzger MJ, Bunce RGH, Jongman RHG, et al (2013) A high-resolution bioclimate map of the world: a unifying framework for global biodiversity research and monitoring. Glob Ecol Biogeogr 22:630-638. doi: 10.1111/geb.12022

Mkhabela MS, Bullock P, Raj S, et al (2011) Crop yield forecasting on the Canadian Prairies using MODIS NDVI data. Agric For Meteorol 151:385-393. doi: 10.1016/j.agrformet.2010.11.012

Mkhabela MS, Mashinini NN (2005) Early maize yield forecasting in the four agro-ecological regions of Swaziland using NDVI data derived from NOAAs-AVHRR. Agric For Meteorol 129:1-9. doi: 10.1016/j.agrformet.2004.12.006

Monfreda C, Ramankutty N, Foley JA (2008) Farming the planet: 2. Geographic distribution of crop areas, yields, physiological types, and net primary production in the year 2000. Global Biogeochem Cycles 22:. doi: 10.1029/2007GB002947

Mueller ND, Gerber JS, Johnston M, et al (2012) Closing yield gaps through nutrient and water management. Nature 490:254-257

Owadi B, Kendle A, Koiwu T (2010) Liberia: The State of Food and Nutrition Security October 2010. World Food Programme

Potter C, Klooster S, Genovese V (2012) Net primary production of terrestrial ecosystems from 2000 to 2009. Clim Change 115:365-378. doi: 10.1007/s10584-012-0460-2

Pradhan P, Fischer G, Van Velthuizen H, et al (2015) Closing yield gaps: How sustainable can we be? PLoS One 10:. doi: 10.1371/journal.pone.0129487

Prince SD, Becker-Reshef I, Rishmawi K (2009) Detection and mapping of long-term land degradation using local net production scaling: Application to Zimbabwe. Remote Sens Environ 113:1046-1057. doi: 10.1016/j.rse.2009.01.016

Rask K, Rask N (2014) Measuring Food Consumption and Production According to Resource Intensity: The Methodology Behind the Cereal Equivalent Approach

Rojas O, Vrieling A, Rembold F (2011) Assessing drought probability for agricultural areas in Africa with coarse resolution remote sensing imagery. Remote Sens Environ 115:343-352. doi: 10.1016/j.rse.2010.09.006

See L, Fritz S, You L, et al (2015) Improved global cropland data as an essential ingredient for food security. Glob Food Sec 4:37-45. doi: 10.1016/j.gfs.2014.10.004

Singh RP, Prasad PV V, Reddy KR (2013) Impacts of Changing Climate and Climate Variability on Seed Production and Seed Industry. In: Sparks DL (ed) Advances in Agronomy, Vol 118. pp 49-110

Tilman D, Balzer C, Hill J, Befort BL (2011) Global food demand and the sustainable intensification of agriculture. Proc Natl Acad Sci 108:20260-20264

van Ittersum MK, Cassman KG, Grassini P, et al (2013) Yield gap analysis with local to global relevance-A review. F Crop Res 143:4-17. doi: 10.1016/j.fcr.2012.09.009

van Ittersum MK, van Bussel LGJ, Wolf J, et al (2016) Can sub-Saharan Africa feed itself? Proc Natl Acad Sci 113:14964-14969. doi: 10.1073/pnas.1610359113

van Wart J, Kersebaum KC, Peng SB, et al (2013) Estimating crop yield potential at regional to national scales. F Crop Res 143:34-43. doi: 10.1016/j.fcr.2012.11.018

van Wart J, van Bussel LGJ, Wolf J, et al (2013) Use of agro-climatic zones to upscale simulated crop yield potential. F Crop Res 143:44-55. doi: http://dx.doi.org/10.1016/j.fcr.2012.11.023 
Vrieling A, de Beurs KM, Brown ME (2011) Variability of African farming systems from phenological analysis of NDVI time series. Clim Change 109:455-477. doi: 10.1007/s10584-011-0049-1

Vrieling A, de Leeuw J, Said MY (2013) Length of Growing Period over Africa: Variability and Trends from 30 Years of NDVI Time Series. Remote Sens 5:982-1000. doi: 10.3390/rs5020982

Waldner F, Fritz S, Di Gregorio A, Defourny P (2015) Mapping priorities to focus cropland mapping activities: Fitness assessment of existing global, regional and national cropland maps. Remote Sens 7:7959-7986. doi: $10.3390 /$ rs70607959

White MA, de Beurs KM, Didan K, et al (2009) Intercomparison, interpretation, and assessment of spring phenology in North America estimated from remote sensing for 1982-2006. Glob Chang Biol 15:2335-2359. doi: 10.1111/j.1365-2486.2009.01910.x

White MA, Thornton PE, Running SW (1997) A continental phenology model for monitoring vegetation responses to interannual climatic variability. Global Biogeochem Cycles 11:217-234. doi: 10.1029/97gb00330 ecological dynamics. Sci Total Environ 506:164-181

Zika M, Erb KH (2009) The global loss of net primary production resulting from human-induced soil degradation 